\title{
Erratum
}

\section{Evaluating the healthiness of chain-restaurant menu items using crowdsourcing: a new method - ERRATUM}

\author{
Lenard I Lesser, Leslie Wu, Timothy B Matthiessen and Harold S Luft
}

First published online 8 August 2016

doi: 10.1017/S1368980016001804. Published by Cambridge University Press, 13 July 2016

The affiliations in the original version of this article incorrectly listed some of the author affiliations. Drs. Wu and Luft are not affiliated with One Medical Group. Leslie Wu was affiliated with the Palo Alto Medical Foundation Research Institute, Palo Alto, CA, USA. Harold S Luft is currently affiliated with the Palo Alto Medical Foundation Research Institute, Palo Alto, CA, USA, as well as the Philip R. Lee Institute for Health Policy Studies, University of California, San Francisco, CA, USA.

\section{Reference}

Lesser LI, Wu L, Matthiessen TB \& Luft HS. Evaluating the healthiness of chain-restaurant menu items using crowdsourcing: a new method. Public Health Nutrition, doi: 10.1017/S1368980016001804. 